\title{
Reflets
}

Revue ontaroise d'intervention sociale et communautaire

\section{Comité Réseau}

\section{Cécile Coderre}

Volume 2, numéro 1, printemps 1996

Contrer la violence subie par les femmes et les enfants en milieu familial

URI : https://id.erudit.org/iderudit/026118ar

DOI : https://doi.org/10.7202/026118ar

Aller au sommaire du numéro

Éditeur(s)

Reflets : Revue ontaroise d'intervention sociale et communautaire

ISSN

1203-4576 (imprimé)

1712-8498 (numérique)

Découvrir la revue

Citer cet article

Coderre, C. (1996). Comité Réseau. Reflets, 2(1), 181-183.

https://doi.org/10.7202/026118ar

Tous droits réservés (C) Reflets : Revue ontaroise d'intervention sociale et communautaire, 1996

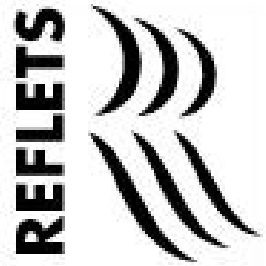

Ce document est protégé par la loi sur le droit d'auteur. L'utilisation des services d'Érudit (y compris la reproduction) est assujettie à sa politique d'utilisation que vous pouvez consulter en ligne.

https://apropos.erudit.org/fr/usagers/politique-dutilisation/ 


\section{Comité Réseau}

\section{Céale $C$ oderre}

É cole de service social, U niversité d'O ttawa

Le C omité $R$ éseau, rassemble plus de 17 agences de la région d'O ttawa- $C$ arleton. $C$ 'est un modèle de concertation qui sert à la fois aux intervenantes qui en font partie, et aux femmes francophones de la région d' $\mathrm{O}$ ttawa- $\mathrm{C}$ arleton.

Ce comité est avant tout un groupement régional d'intervenantes féministes francophones qui se mobilisent et agissent en concertation pour contrer la violence faite aux femmes. Ce groupement est à la fois un lieu d'entraide, de soutien et d'échange, et une tribune d'action sociale et politique.

Le C omité, créé en 1988, oeuvre égal ement pour le maintien et le développement des services en français pour les femmes de la région d' $\mathrm{O}$ ttawa- $\mathrm{C}$ arleton. $\mathrm{C}$ 'est d'ailleurs ces raisons qui ont amené la formation de ce comité, et plus particulièrement le besoin de briser l'isolement que ces femmes vivaient en tant que francophones.

Les services offerts par le Comité ne représentent pas de I'intervention directe auprès des femmes violentées, mais de façon indirecte, le Comité intervient auprès de ces femmes. À l'aide de colloques, de forums organisés dans le but d'informer et de créer desalliances avec les autres intervenantesfrancophones concernées par la problématique de la violence faite aux femmes.

A u niveau de la formation et du perfectionnement, cesactivités leur permettent de mieux connaitre les intérêts, les aptitudes et les expériences de chacune des membres, et ensuite de partager les expertises et d'organiser des sessions de formation (avec des personnes ressources de l'extérieur) pour les membres du Comité. 
La formation, à ce niveau, se fait à partir de l'expertise, de l'expérience et des interêts personnels des membres du Comité. C haque séance de formation a pour but d'offrir du ressourcement, et de permettre aux intervenantes de se perfectionner dans leur travail. D ivers thèmes et formations ont été offerts depuis 1992. N ous les énumérons en suivant l'ordre chronologique: céativité, dévicimisation, femmes et colère, femmes et toxicomanie, formation sur les médias, lobbying, atelier judiciaire sur la séparation et le divorce, et D ialogue entre lesbiennes et hétérosexuelles.

En s'impliquant de façon active sur le plan politique, le Comité a pu établir, au cours des dernières années, une grande crédibilité auprès des autres groupes anglophones et francophones impliqués dans la problématique de la violence faite aux femmes.

C'est par l'organisation de forum sur les approches privilégiées auprès des femmes violentées qu'elles ont pu mieux définir leur spécificité. U n deuxième forum avait pour objectif de sensibiliser les participantes à la réalité des femmes immigrantes, surtout en ce qui concerne les obstacles auxquels ces dernières font face. C eci a également permis de connaître les services en place pour les femmes immigrantes francophones, et de renforcer les liens avec les communautés ethnoculturelles. Avec l'organisation de ce forum, le C omité R éseau avait également pour but de se faire connaître auprès des femmes immigrantes et d'encourager ainsi leur participation au Comité.

D e façon plus précise, le C omité se penche en particulier sur la problématique de la violence conjugale. D epuisquelquestemps, les membres s'intéressent au dossier des agressions à caractère sexuel. Elles sont d'ailleurs impliquées dans différents organismes qui travaillent à la mise sur pied de nouveaux services en français pour les femmes qui ont été agressées sexuellement.

Le nouveau défi qui se pose au Comité R éseau touche l'inclusion des survivantes à la composition du groupe. Le recrutement s'est d'ailleurs effectué en janvier 1994. Par la suite, le Comité a établi une ébauche de politique pour accueillir et intégrer les femmes survivantes au Comité $R$ éseau. $U n$ autre défi de taille est la viabilité du R éseau quand il n'y aura plus de subvention pour défrayer les coûts du salaire de la coordonnatrice. 
Enfin deux autres priorités sont toujours présentes, soit l'alliance avec les femmes immigrantes appartenant à des minorités raciales, et l'intégration du «Plan de services pour les femmes violentées». 